\title{
UM ESTUDO SOBRE AS CARACTERIISTICAS DO MÉTODO DELPHI E DE GRUPO FOCAL, COMO TÉCNICAS NA OBTENÇÃO DE DADOS EM PESQUISAS EXPLORATÓRIAS
}

\author{
A STUDY ON THE CHARACTERISTICS OF THE \\ DELPHI METHOD AND FOCUS GROUP AS TECHNIQUES \\ TO OBTAIN DATA IN EXPLORATORY RESEARCH
}

\author{
Recebido 13/08/2012 \\ Aceito $07 / 01 / 2013$ \\ Lorimar Francisco Munaretto ${ }^{1}$ \\ Hamilton Luiz Corrêa² \\ Júlio Araújo Carneiro da Cunha ${ }^{3}$
}

\section{RESUMO}

O presente estudo teve por objetivo descrever as principais características do método Delphi e de grupo focal, como técnicas de obtenção de dados em pesquisas exploratórias. Trata-se de um estudo bibliográfico, realizado com materiais publicados em livros, revistas, redes eletrônicas etc., de fontes primárias e secundárias. Os resultados demonstram que a técnica de grupo focal não apresenta anonimato dos participantes, como ocorre no Delphi, e que a interação entre os participantes é realizada por feedback não controlado, ao contrário do que ocorre no método Delphi. O método de pesquisa Delphi é realizado por meio de questionários estruturados, aplicados aos especialistas, de forma intensiva e intercalada, em diversos rounds. Os principais benefícios da técnica de grupo focal para as pesquisas exploratórias estão em: i) auxiliar na formulação de hipóteses, pois a discussão sobre dado tema leva à clareza de pensamento, ajudando a expressar proposições de pesquisa; ii) auxiliar na identificação de conceitos relevantes de uma pesquisa, que pode ser a característica de um produto ou de um serviço, atuando na definição operacional de um conceito na identificação e testagem de novas ideias de pesquisa. Denota-se que ambos os métodos, Delphi e grupo focal, apresentam contribuições eficientes no levantamento de dados para as pesquisas de natureza exploratória.

Palavras Chave: Pesquisa exploratória; Delphi; Grupo focal.

\footnotetext{
${ }^{1}$ Possui graduação em Ciências Contábeis pela Universidade Regional Integrada do Alto Uruguai e das Missões - URI/FW, Especialização em Planejamento Tributário pela Universidade Federal de Santa Catarina - UFSC, Mestrado em Administração pela Universidade Federal de Santa Catarina - UFSC. Atualmente é Doutorando em Administração pela FEA/USP/SP e professor assistente da Universidade Federal de Santa Maria - UFSM/CESNORS. Frederico Westphalen, Rio Grande do Sul, Brasil. E-mail: franciscomunaretto@gmail.com.

${ }^{2}$ Possui graduação em Administração pela Universidade de São Paulo - USP, mestrado em Administração pela Universidade de São Paulo - USP, doutorado em Administração pela Universidade de São Paulo - USP e pós-doutorado pela Found Leon Bekaert. Atualmente é Professor da Universidade de São Paulo - USP. São Paulo, São Paulo, Brasil. E-mail: hamillco@usp.br.

${ }^{3}$ Possui graduação em Ciências Econômicas pela Universidade de São Paulo - USP, graduação em Administração pela Universidade de Ribeirão Preto - UNAERP, graduação em Comércio Exterior pela Universidade de Ribeirão Preto - UNAERP, graduação em Ciências Contábeis pela Universidade de São Paulo - USP, mestrado em Administração de Organizações pela Universidade de São Paulo - USP, Doutorado em Administração pela Universidade de São Paulo - USP e Doutorado em Recursos Humanos pela Faculdade Getúlio Vargas - FGV. Atualmente é professor titular do Programa de Mestrado em Administração da Universidade Paulista. São Paulo, São Paulo, Brasil. E-mail: juliocunha@yahoo.com.
} 
This study aimed to describe the main characteristics of the Delphi method and focus group as data collection techniques in exploratory research. This is a bibliographic study, conducted with materials published in books, magazines, electronic networks etc.., Of primary and secondary sources. The results demonstrate that the focus group technique has no anonymity of the participants, as in Delphi, and that the interaction between the participants is carried out by uncontrolled feedback, unlike what occurs in the Delphi method. The research Delphie accomplished through structured questionnaires applied to experts, intensively and interspersed in several rounds. The main benefits of focus group techniques for exploratory research are: i) to assist in the formulation of hypotheses, since the discussion on specific topic leads to clarity of thought, helping to express research propositions ii) assist in identifying relevant concepts of research, which may be characteristic of a product or a service, working in the operational definition of a concept in the identification and testing of new research ideas. Denotes that both methods, Delphi and focus group contributions have efficient data collection for research of an exploratory nature.

Keywords: Exploratory research, Delphi; Focus group.

\section{INTRODUÇÃO}

De acordo com Collis e Hussey (2005), diversos podem ser os tipos de pesquisa na área da Administração. Para os autores, cada classificação sustenta-se conforme os aspectos da pesquisa acadêmica, podendo, então, haver uma tipologia baseada na orientação quanto ao objetivo, ao processo, à lógica ou ao resultado da pesquisa. Quando se aborda, especificamente, a orientação quanto ao objetivo de pesquisa, leva-se em consideração, também, seu plano de execução, que busca oferecer informações relevantes para as questões de pesquisa (HAIR Jr. et al., 2007). Os planos de pesquisa da área da Administração podem ser agrupados em uma de três categorias: i) descritivo; ii) explicativo ou causal; iii) exploratório (HAIR Jr. et al., 2007).

Analisando cada uma dessas categorias, percebe-se, primeiramente, que as pesquisas descritivas possuem como principal objetivo avaliar e descrever características pertinentes à questão de pesquisa (COLLIS; HUSSEY, 2005), ou seja, as características de determinada população, fenômeno ou o estabelecimento de relações entre as variáveis (GIL, 1999). Geralmente, a sua coleta de dados é realizada por meio de algum tipo de processo de entrevista estruturada, a maioria dos estudos são realizados para testar hipóteses e grande parte das pesquisas são surveys.

Por sua vez, as pesquisas explicativas visam identificar os fatores que determinam ou contribuem para a ocorrência dos fenômenos (GIL, 1999). Para Andrade (2002), a pesquisa explicativa é um tipo de pesquisa mais complexa que as outras, pois, além de registrar, analisar, classificar e interpretar os fenômenos estudados, procura delimitar seus fatores determinantes. É a pesquisa que procura explicar a razão das coisas, ao aprofundar o conhecimento sobre a realidade.

Por fim, as pesquisas exploratórias são úteis quando o tema em estudo foi pouco explorado. A pesquisa exploratória é desenvolvida no sentido de proporcionar uma visão geral acerca de determinado fato, procurando buscar "padrões, ideias ou hipóteses, em vez de testar ou confirmar uma hipótese" (COLLIS; HUSSEY, 2005, p.24). Isso ocorre porque, na pesquisa exploratória, busca-se conhecer, mais profundamente, o tema abordado, de modo a torná-lo mais claro. Portanto, a pesquisa exploratória segue uma orientação que se volta para a descoberta.

Ao tratar de pesquisas exploratórias, por vezes, o pesquisador dispõe de incentivos e recursos que possibilitam realizar pesquisas por meio de diversos métodos, de forma a utilizarse de triangulações para confirmar e aprofundar suas descobertas (DENZIN, 1978; 2010; JICK, 1979; EGAN et al., 1995; FLICK, 2009). Trata-se de uma estratégia com o uso de múltiplas técnicas 
que serve como uma "combinação de perspectivas e métodos de pesquisas apropriados que sejam convenientes para levar em conta o máximo possível de aspectos distintos de um mesmo problema" (FLICK, 2009, p. 105). Todavia, a realidade do pesquisador, em especial no Brasil, não conta sempre com os recursos financeiros e temporais necessários para a aplicação de diversas técnicas, tampouco com a disposição de uma amostra para submeter a um processo de pesquisa por diversas vezes e sob múltiplas perspectivas. Diante disso, o pesquisador, comumente, acaba optando pela técnica mais adequada aos seus recursos e ao seu objetivo de pesquisa, ou seja, geralmente, ele acaba tendo que enfrentar trade-offs entre as diferentes técnicas de pesquisa e precisa tratá-las não como complementares, mas como opções a serem feitas e, posteriormente, seguidas de maneira singular. Para fazer tal escolha de maneira que ela tenha substrato e sustentação, o pesquisador deve estar atento para compreender as vantagens e desvantagens de cada uma de suas opções, bem como suas dessemelhanças.

Em contrapartida, grande parte dos estudos que se focam em estabelecer relações entre diferentes técnicas de coleta de consenso entre especialistas (e.g. EGAN et al., 1995; LANDETA et al., 2011) busca formas de uni-las e criar algo de maior consistência metodológica, em detrimento do emprego de relações pareadas. Isso justifica-se, a priori, porque a busca do consenso entre especialistas e não o acordo entre eles é uma metodologia de pesquisa multidisciplinar rigorosa (CORTÉS-REYES, 2012), a qual requer diversos complementos e intersecções entre as técnicas existentes. Todavia, entender as diferenças comparativas e paralelas entre diferentes técnicas é algo mais factível e adaptável à realidade do pesquisador brasileiro. Por isso, a demanda local concentra-se em reflexões que apontarão técnicas adequadas aos diferentes contextos de pesquisa, cujas restrições de recursos para desenvolvimento de pesquisas são fatores determinantes. Trata-se de uma realidade mais factível para o pesquisador se deparar no contexto nacional, o que justifica esse tipo de apontamento em detrimento de se estabelecerem procedimentos metodológicos mais amplos e complexos. É nessa especificidade que o presente estudo se soma à construção de conhecimento da área de Administração, colocando em paralelo duas técnicas de pesquisa.

Frente a esse embate de opções a serem escolhidas pelo pesquisador, especificamente nos estudos exploratórios, o presente estudo foca-se no dilema de escolha entre duas técnicas específicas: a Delphi e a de grupo focal (GF, Focus Group). Escolheram-se essas duas técnicas por serem formas tradicionais de coleta de dados de especialistas em determinado assunto para o levantamento de informações em pesquisa de campo, mas que se diferenciam pelo fato de contar com as respostas individuais dos participantes e outra contar com a interação social dos participantes. Ambas as técnicas têm como objetivo propor uma visão de determinado grupo sobre um fenômeno, mas a condução delas dá-se de forma diferente, podendo, assim, ter resultados diferentes. Cabe, então, ao pesquisador determinar qual das duas técnicas é a mais adequada e se encaixa melhor no seu contexto de pesquisa e na sua disponibilidade de recursos.

Portanto, o objetivo desse ensaio é descrever as principais características do método Delphi e do método de grupo focal, como técnicas de entrevista exploratórias, de forma a estabelecer um quadro comparativo entre os dois métodos que auxilie o processo de escolha do mais adequado para o pesquisador.

O presente estudo está estruturado em quatro seções. Além da primeira seção, que apresenta o tema em estudo, a segunda seção apresenta a revisão de literatura básica, que introduz os conceitos primários sobre o Delphi e o grupo focal. A terceira parte estabelece um quadro comparativo entre as duas técnicas abordadas neste estudo. A quarta etapa explana as conclusões e a apresentação das discussões finais. Por fim, a última parte do estudo apresenta 
algumas limitações do mesmo, bem como apresenta algumas recomendações para continuidade e construção de conhecimento sobre o tema abordado.

\section{REVISÃO DE LITERATURA}

Na sequência, apresenta-se uma breve revisão teórica sobre a pesquisa exploratória no campo da Administração e, após, descreve-se sobre a técnica Delphi e a de grupo focal, explicitando detalhes e procedimentos para o emprego de cada uma delas, assim como as vantagens e desvantagens de suas aplicações.

\subsection{Pesquisas exploratórias em Administração}

De forma genérica, a pesquisa exploratória é empregada em casos nos quais existe pouco conhecimento sobre determinado assunto e, geralmente, requer do pesquisador uma pesquisa de campo (MARION; DIAS; TRALDI, 2002). Assim, essa pesquisa visa descobrir informações iniciais de uma realidade para que se possa formular, posteriormente, hipóteses sobre ela. Podese afirmar que as pesquisas exploratórias têm como objetivo principal o aprimoramento de ideias ou a confirmaç̧̃̃o de intuições. Assim, busca entender as razões e motivações para determinadas atitudes e comportamentos das pessoas.

Quanto ao planejamento, a pesquisa é bastante flexível, de modo que possibilita a consideração dos mais variados aspectos relativos ao fato estudado. Como o pesquisador não sabe ao certo com qual realidade vai se deparar, um planejamento bem estruturado acaba sendo pouco factível. Ainda que existam manuais sobre como conduzir esse tipo de pesquisa (e.g. GLASER; STRAUSS, 1967), não se pode afirmar que existe um procedimento definido e rígido, pelo contrário, defende-se a flexibilidade de processos.

$\mathrm{Na}$ área das Ciências Sociais, a orientação da pesquisa qualitativa abrange mais que um processo científico específico ou uma abordagem metodológica, tal como defende Stebbins (2001), porque é uma orientação proveniente do estilo de vida do pesquisador. Isto é, a exploração dos fatos para a compreensão de uma realidade pouco estudada é algo que, a priori, pode ser confuso e sem direção definida, além de consumir muito tempo e poder trazer resultados frustrantes ao pesquisador, que deve gostar desse tipo de trabalho, ter disposição para ele e, preferencialmente, possuir experiência para a imersão nesse tipo de realidade pouco estruturada do ponto de vista formal e em termos de modelagem.

Especificamente, na Administração, Schindler e Cooper (2001, p.222) apontam que essa pesquisa tem por objetivo:

- Aumentar o entendimento do problema de administração;

- Saber como outras pessoas trataram e/ou resolveram problemas similares ao seu problema ou à sua questão de administração;

- Reunir informações anteriores sobre o tópico para refinar a questão de pesquisa;

- Identificar informações que possam ser reunidas para formular as questões investigativas;

- Identificar fontes e questões reais que possam ser usadas como questões de mensuração;

- Identificar fontes e estruturas reais de amostra que possam ser usadas no projeto de amostragem. 
Com ampla aplicabilidade na área da Administração, as pesquisas exploratórias podem ser realizadas para diferentes propósitos. Torna-se inegável a importância e contribuição da pesquisa exploratória para a academia da Administração. Todavia, não se pode limitar sua importância apenas para esse escopo. A pesquisa exploratória é proveitosa, também, no cotidiano das organizações.

Por exemplo, na área de Pesquisa de Marketing, Révillion (2001) explica que a pesquisa exploratória pode estudar as reações de um grupo de consumidores ao lançamento de um novo produto, ou então descobrir quais as variáveis que são avaliadas pelo consumidor na escolha ou na preferência de determinada marca. Por isso, é "apropriada para os primeiros estágios da investigação, quando a familiaridade, o conhecimento e a compreensão do fenômeno por parte do pesquisador são geralmente insuficientes ou inexistentes" (MATTAR, 1994, p.84).

Para Hair Jr. et al. (2005), a pesquisa exploratória é proveitosa também para indústrias altamente inovadoras, como, por exemplo, as empresas Microsoft, IBM, Dupont, que a utiliza para criar novos produtos e serviços, bem como para verificar como as tecnologias atendem às reais necessidades da empresa ou do consumidor.

Assim, percebe-se a ampla aplicabilidade da pesquisa exploratória na Administração, pois ela pode ser utilizada com diferentes objetivos e finalidades. Na sequência, descrevemse, especificamente, as técnicas Delphi e as de entrevista exploratória de grupo focal, sob a perspectiva exploratória de coleta de dados que esses métodos podem trazer.

\subsection{Delphi}

Em meados do século XX, os pesquisadores Olaf Helmer e Norman Dakley da Rand Corporation (empresa ligada a projetos de defesa militar da força aérea dos Estados Unidos) utilizaram-se da opinião de especialistas para suas fundamentações científicas (LINSTONE; TUROFF, 1975). No estudo realizado por eles, o objetivo era obter o consenso da opinião dos especialistas da maneira mais objetiva possível por meio de uma série de questionamentos a serem feito. A partir desse estudo de busca de opinião de especialistas como forma de validar, cientificamente, informações de campo, diversos métodos e técnicas de coleta de dados por meio de opiniões de especialistas surgiram, cujo mais popular é o Delphi, oriundo do nome do projeto desenvolvido pela Rand Corporation e cuja inspiração se deu pela antiga mitologia grega sobre o antigo oráculo de Delfos, dedicado a Apolo (LIMA et al., 2008). De acordo com Linstone e Turrof (1975), a pesquisa foi financiada pela força aérea dos Estados Unidos e buscava a opinião de um estrategista soviético sobre quais seriam os alvos mais apropriados para as bombas atômicas e qual a quantidade de bombas necessárias para reduzir a capacidade industrial americana em determinada quantidade. Faz-se importante ressaltar, que, por mais que o Delphi tenha sido desenvolvido num contexto militar, sua utilização expande-se para diversas áreas do conhecimento e diferentes contextos (CARNEIRO DA CUNHA, 2011).

De acordo com seus precursores, Dalkey e Helmer (1963), o método Delphi tem como objetivo obter o mais confiável consenso de opiniões de um grupo de especialistas, por meio de uma série de questionários intensivos, intercalados por feedbacks controlados de opiniões. Assim, a partir desse desenvolvimento metodológico, o Delphi é compreendido como uma técnica sistemática para coletar a opinião, válidas cientificamente, de especialistas sobre determinado assunto (DALKEY, 1969).

Numa segunda definição, proposta por Meyrick (2003), o método visa buscar a opinião de especialistas sobre uma determinada questão, provendo feedback controlado acerca das opiniões expostas, e coletando suas opiniões novamente, permitindo, assim, que os especialistas respondam às entradas provenientes de painéis com outros membros. 
A quantidade de especialistas envolvidos num grupo Delphi tem efeito direto no potencial de ideias a serem consideradas na geração de informações e na quantidade de informações com que o pesquisador pretende trabalhar (HASSON et al., 2000). Todavia, não existe um consenso na academia sobre a quantidade ideal de participantes num grupo Delphi, porque essa quantidade depende do escopo e contexto da pesquisa (VERGARA, 2008) e de fatores extrínsecos ao pesquisador, como, por exemplo, a disponibilidade de especialistas para participar.

Por fim, as concordâncias de opiniões dos especialistas sobre um assunto ocorrem sobre quatro pilares fundamentais, que são: (i) o anonimato dos participantes da pesquisa; (ii) a consulta aos especialistas para a coleta de dados; (iii) a aplicação de rodadas interativas e com feedback, de forma que os participantes possam rever suas opiniões e refletir sobre elas; (iv) a busca por consenso, oriunda da avaliação do ponto de vista levantado pelo grupo (SÁFADI, 2001). Nessa mesma perspectiva, Oliveira (2008) apresenta as principais características do método Delphi, apontando suas vantagens e suas desvantagens, já que, segundo Benarie (1988), comumente os usuários do Delphi não estão atentos às desvantagens que a técnica traz.

O Quadro 1 apresenta as principais características do método Delphi, bem com suas vantagens e desvantagens.

Quadro 1 - Características do método Delphi e suas vantagens e desvantagens.

\begin{tabular}{|c|c|c|}
\hline Características & Vantagens & Desvantagens \\
\hline Anonimato & $\begin{array}{l}\text { Igualdade de expressão de ideias. O anonima- } \\
\text { to faz com que a interatividade aconteça com } \\
\text { maior espontaneidade e que assuntos críticos } \\
\text { ou polêmicos possam ser melhor discutidos e } \\
\text { apresentados pelos participantes. }\end{array}$ & $\begin{array}{l}\text { Ao responder um questionário sozinho, } \\
\text { o respondente pode não se lembrar de } \\
\text { tudo que pensa sobre o assunto ou pode } \\
\text { não se ater a pontos sobre os quais ain- } \\
\text { da não refletiu. }\end{array}$ \\
\hline Feedback & $\begin{array}{l}\text { Redução de ruídos. Evita desvios no objetivo } \\
\text { do estudo. Fixação no grupo das metas pro- } \\
\text { postas. Possibilidade de revisão de opiniões } \\
\text { pelos participantes. }\end{array}$ & $\begin{array}{l}\text { Pode determinar o sucesso ou o insuces- } \\
\text { so do método. Risco de excluir da análise } \\
\text { pontos de discordância. }\end{array}$ \\
\hline Flexibilidade & $\begin{array}{l}\text { No decorrer das discussões os participantes re- } \\
\text { cebem opiniões, comentários e argumentações } \\
\text { dos outros especialistas, podendo, assim, rever } \\
\text { suas posições diante do assunto pesquisado. As } \\
\text { barreiras comunicacionais são superadas. }\end{array}$ & $\begin{array}{l}\text { Dependendo de como serão apresentados } \\
\text { os resultados e feedbacks, é possível que } \\
\text { se criem consensos, forçados ou artificiais, } \\
\text { em que os respondentes podem aceitar } \\
\text { de forma passiva a opinião de outros es- } \\
\text { pecialistas e passar a defendê-las. }\end{array}$ \\
\hline $\begin{array}{l}\text { Uso de } \\
\text { especialistas }\end{array}$ & $\begin{array}{l}\text { São formados conceitos, julgamentos, aprecia- } \\
\text { ções e opiniões confiáveis a respeito do assunto. }\end{array}$ & $\begin{array}{l}\text { Possibilidade de obter consenso de for- } \\
\text { ma demasiado rápida. }\end{array}$ \\
\hline Consenso & $\begin{array}{l}\text { Sinergia de opinião entre os especialistas. } \\
\text { Identificação do motivo de divergência de opi- } \\
\text { nião. }\end{array}$ & Risco de criar um consenso artificial. \\
\hline Interatividade & $\begin{array}{l}\text { A interatividade foge de uma conjuntura hie- } \\
\text { rárquica, pois formata as respostas e, em se- } \\
\text { guida, faz com que elas sejam partilhadas. } \\
\text { Adequação das respostas, pois tende a excluir } \\
\text { excentricidades que estejam fora do contex- } \\
\text { to solicitado. Aprendizado recíproco entre os } \\
\text { respondentes. }\end{array}$ & $\begin{array}{l}\text { Rodadas interativas realizadas em rede } \\
\text { são apontadas como desvantagens por } \\
\text { críticos ao método. Apesar de tornar o } \\
\text { processo mais rápido e menos oneroso, } \\
\text { o sincronismo possibilitado pela inter- } \\
\text { net, contraria o beneficio de obter res- } \\
\text { postas mais elaboradas. }\end{array}$ \\
\hline
\end{tabular}

Fonte: Adaptado de OLIVEIRA, J. S. P.; COSTA, M. M.; WILLE, M. F.C.; MARCHIORI, P. Z. Introdução ao Método Delphi. Curitiba: Mundo Material, 2008 (manual didático).

De acordo com Sackman (1975), o método Delphi apresenta a seguinte configuração:

a. O formato é, tipicamente, mas nem sempre, um questionário do tipo "papel e lápis", que pode ser aplicado por via do correio, em uma entrevista pessoal ou em uma 
sessão, interativa ou online. A técnica básica de apresentação e coleta dos dados é o questionário formal, estruturado para cada caso;

b. O questionário consiste em uma série de itens, utilizando escalas semelhantes ou diferentes, quantitativas ou qualitativas, de acordo com os objetivos do estudo;

c. Os itens do questionário podem ser gerados pelo coordenador da pesquisa, pelos participantes, ou por ambos;

d. O questionário é acompanhado por algumas instruções, diretrizes do jogo;

e. O questionário é aplicado aos participantes em duas ou mais rodadas, os participantes respondem aos itens objetivos escalados e podem ou não responder às solicitações verbais abertas;

f. Cada momento de interação é acompanhado por alguma forma de feedback estatístico, que, geralmente, envolve uma medida de tendência central, alguma medida de dispersão, ou ainda, de distribuição de frequência absoluta das respostas de cada item.

A Figura 1 apresenta as etapas a serem seguidas para a realização da pesquisa Delphi.

Figura 1 - Etapas do método Delphi.

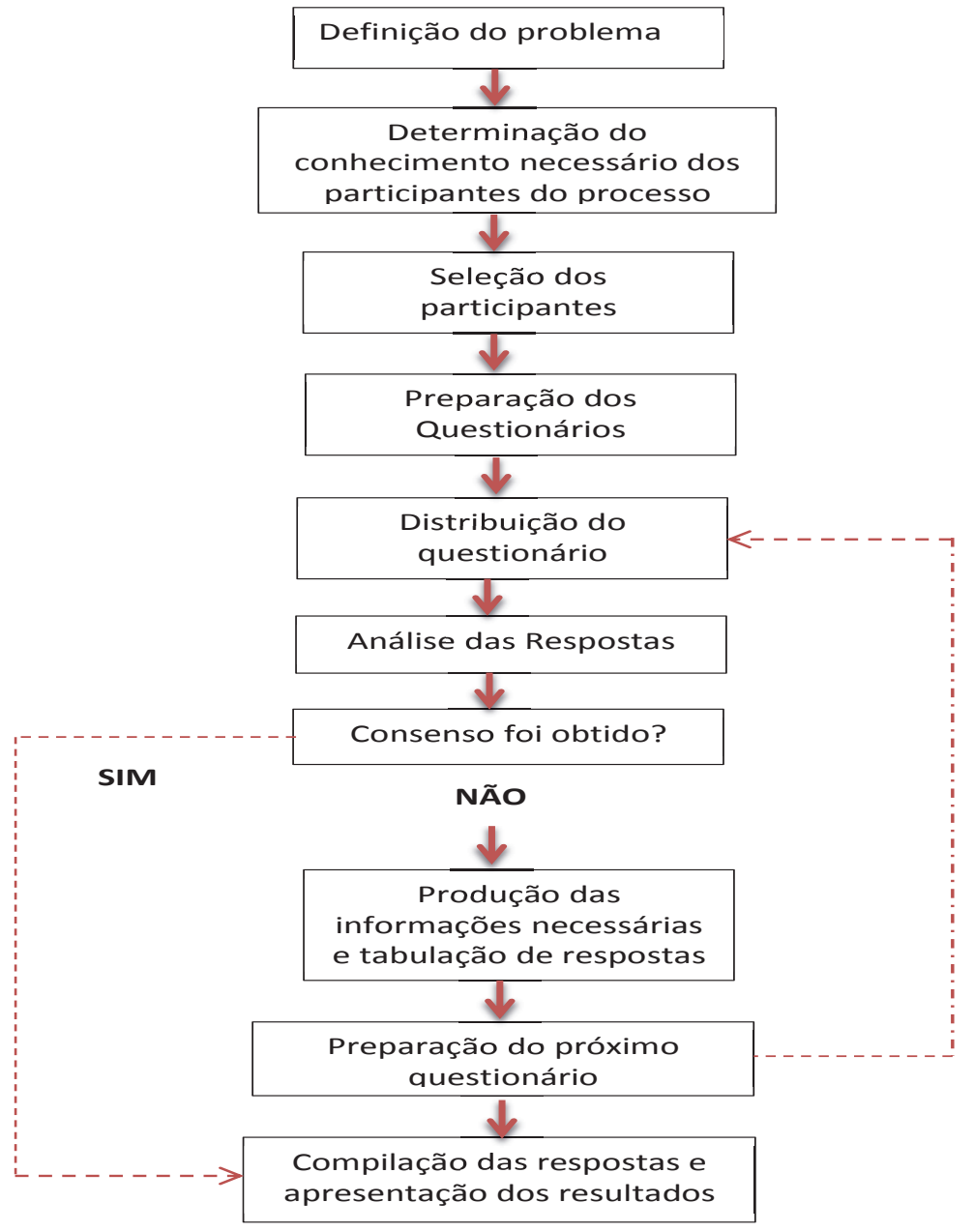

Fonte: Adaptado de OLIVEIRA, J. S. P.; COSTA, M. M.; WILLE, M. F.C.; MARCHIORI, P. Z. Introdução ao Método Delphi. Curitiba: Mundo Material, 2008 (manual didático). 
Conforme as etapas propostas na Figura 1, a pesquisa inicia com a definição do problema objeto da pesquisa. Após são selecionados os especialistas da área do assunto problema, que, voluntariamente, desejam participar da pesquisa. Na sequência, preparam-se os questionários, que são distribuídos aos especialistas, tendo em vista obter o parecer do especialista com base em sua experiência e conhecimento. A partir do retorno dos questionários são analisadas as respostas, buscando-se consenso da maior parte dos especialistas em relação ao assunto. A partir desse ponto, podem haver duas situações: (i) haver consenso (concordância) entre os especialistas, através da compilação de respostas e apresentação dos resultados finais do estudo; ou (ii) caso haja divergência entre as respostas dos especialistas, prepara-se o próximo questionário com os pontos divergentes ( $2^{\circ}$ round) e encaminha-se, novamente, o questionário aos especialistas para a obtenção do consenso. Assim, sucessivamente, busca-se, através de rodadas de questionários com os especialistas, obter o consenso, em relação ao assunto (tema) tratado.

\subsection{Grupo focal}

A técnica de grupo focal foi estruturada, inicialmente, por Robert Merton e seus colaboradores, na década de 1940. Essa técnica foi utilizada em pesquisas sociais realizadas com soldados durante a II Guerra Mundial, cujo objetivo era conhecer a eficácia do material de treinamento para as tropas e o efeito de propagandas persuasivas (DE ANTONI et al., 2001).

Conceitualmente, a pesquisa de grupo focal é uma técnica que é utilizada em pesquisas qualitativas com o objetivo de coletar dados através da interação grupal (DE ANTONI et al., 2001). Essa técnica consiste em reunir um grupo de pessoas, preferencialmente especialistas, para que o pesquisador possa entender como elas se sentem ou pensam a respeito de determinado fenômeno (KRUGER; CASEY, 2000). Essa discussão é conduzida por um pesquisador ou moderador treinado (entrevistador), o qual traz consigo uma lista, previamente preparada, dos tópicos a serem discutidos e permite que os participantes respondam às perguntas propostas com suas próprias palavras.

Assim, cada resposta específica é acompanhada de questões de sondagem, tais como "Alguma coisa mais vem à sua mente?". Não obstante, aplica-se a técnica da sondagem dos "por quês" (HAIR Jr. et al., 2007, p. 85), até que se esgote o assunto em meio ao grupo. Por isso, Morgan (1997) afirma que os grupos focais podem ser utilizados para a coleta de dados qualitativos preliminares sobre determinada questão de pesquisa, servindo, assim, de fonte primária para um dado coletado, e, posteriormente, justificando o uso da técnica como constituinte de uma perspectiva exploratória.

Nesse sentido, Debus (2004, p. 3) afirma que o grupo focal é "uma técnica, que se apropriou da dinâmica de grupo, permitindo a um pequeno número de participantes, guiados por um moderador, tendo em vista alcançar níveis crescentes de compreensão e aprofundamento de um tema a ser estudado". Assim, ocorrem reuniões de grupo focal, nas quais os participantes expressam suas opiniões, pensamentos e experiências relativas ao assunto proposto pelo pesquisador moderador (MORGAN; SPANISH, 1984). Nesses encontros, além de os participantes não apenas exporem suas opiniões, o coordenador/moderador os incentiva a participar, possibilitando o resgate de informações que os participantes poderiam não se recordar numa entrevista individual ou, ainda, trazer à tona temas, relacionados ao assunto central, sobre os quais eles ainda não refletiram.

No entanto, não se pode esquecer que as técnicas de grupo focal são importantes para explorar percepções coletivas e não individuais (SIM, 1998). As características individuais dos membros do grupo são apenas uma parcela de todo o contexto a ser analisado (STEWART et al., 2007). Portanto, ao se analisar as informações coletadas no grupo focal, é importante que o pesquisador esteja atento aos consensos e às exceções expostas pelo grupo, pois eles podem indicar não o que o grupo, como 
um todo sente, mas aquilo que se expôs mais fortemente na discussão (SIM, 1998). Por isso, faz-se importante garantir a participação de todos nas sessões de grupo focal.

Portanto, o grupo focal é um fenômeno social que traz benefícios recorrentes da própria interação e socialização do grupo debatedor (STEWART et al., 2007). Não é necessário haver uma votação ou um consenso quanto a uma problemática, é necessário apenas que eles exponham suas opiniões e que elas sejam debatidas, pois o intuito é que exista identificação dos padrões e das tendências dos grupos analisados (KRUEGER; CASEY, 2000), ou seja, ainda que haja uma opinião preponderante entre a maioria dos participantes do grupo, não necessariamente existe um consenso ou uma opinião grupal.

Em relação aos participantes do grupo focal, os indivíduos devem ser semelhantes entre si, ou melhor, os grupos devem ser homogêneos (GREENBAUM, 1998). É importante existir características semelhantes entre eles, relativas ao tópico a ser abordado pelo grupo focal (KRUEGER; CASEY, 2000). O moderador/pesquisador deve atentar para as características individuais dos participantes, a fim de deixá-los mais à vontade nas discussões (STEWART et al., 2007). Deve haver um clima permissivo e confortável que permita que os participantes se sintam à vontade para expor suas opiniões (KRUEGER; CASEY, 2000).

Para que isso ocorra, é necessário haver uma quantidade de participantes que possa favorecer a criação de um ambiente propulsor aos interesses do pesquisador, bem como seus objetivos de estudo. No entanto, não existe um consenso entre os estudiosos sobre essa quantidade ideal de participantes. Por um lado, Krueger e Casey (2000) afirmam que o tamanho ideal de participantes de um grupo focal varia de seis a oito participantes. Por outro, Morgan e Spanish (1984) indicam que o grupo deve ser de quatro a dez pessoas. Hair et al. (2007) defendem que o ideal é haver entre oito e doze pessoas e, por último, Gomes e Barbosa (2009) acreditam que o ideal é de cinco a doze participantes. Sobre isso, Bloor et al. (2001) afirmam que o importante é que esses grupos tenham tamanho adequado conforme a disponibilidade de participantes e do pesquisador, levando em consideração o tamanho da infraestrutura disponível para os encontros e a quantidade de pessoas que o pesquisador julgar adequada para a discussão proposta.

Outro cuidado relevante ao se realizar um grupo focal é referente ao moderador/ pesquisador. Segundo Hughes e Dumont (1993), ele deve ser capaz de identificar o conhecimento cultural e ter compartilhar da linguagem dos participantes para poder mediar as discussões. As intervenções do moderador/pesquisador devem ser as mínimas possíveis, levantando situações e questões, direcionando as discussões e assegurando que as questões de pesquisa serão discutidas e respondidas por todos (GREENBAUM, 1998).

O moderador/pesquisador é o responsável por apresentar os temas a serem discutidos, previamente descritos num roteiro, além de ser responsável por utilizar técnicas de investigação em busca de opiniões, experiências, ideias, observações, preferências, necessidades e outras informações. O moderador tem como papel incentivar a participação de todos os indivíduos participantes, evitando que a opinião de algum deles predomine sobre as demais. O moderador ainda conduz a discussão de modo que ela se mantenha dentro dos tópicos de interesse da pesquisa. Por fim, o moderador não deve fazer julgamentos sobre as informações apresentadas, mas salientar as ideias relevantes e encorajar os participantes a darem segmento às perguntas apresentadas. Pontua-se que o moderador ou o seu assistente são responsáveis por anotar ou gravar as ideias obtidas junto aos participantes.

Portanto, o moderador tem o papel fundamental de administrar os processos de pesquisa, que envolvem preparação, implementação e procedimentos pós-grupo focal, principalmente, a análise das informações coletadas (GREENBAUM, 1998). As fases de trabalho para um grupo focal, 
propostas por Greenbaum (1998), podem ser divididas em três: (i) preparação do grupo focal, na qual o moderador elabora a proposta, desenvolve as metas de pesquisa, determinação dos critérios para a escolha dos participantes, proposta de um esquema de logística adequado, desenvolvimento de um guia para o moderador - que servirá de documento mestre, apresentando todos os passos e as informações necessárias para a condução do grupo focal -, apresentação de estímulos externos para incentivar a discussão, confirmação de que os participantes comparecerão e participarão do grupo focal; (ii) implementação - que ocorre durante a condução do grupo focal e depende da revisão dos preparativos realizados anteriormente -,na qual o moderador reúne os participantes, coordena as interações entre eles, conduz os grupos e suas respectivas discussões e conclui o processo dentro do tempo proposto; (iii) procedimentos pós-grupo focal, que consistem em manter os relatos do que ocorre após a consecução do grupo focal e na gravação e análise das discussões.

Diante do exposto, Gomes e Barbosa (2009) defendem que as principais características de um grupo focal são: (i) cada grupo é organizado com pequeno número de pessoas (entre cinco e doze) para incentivar a interação entre os membros; (ii) cada sessão dura de uma a duas horas; (iii) a conversação concentra-se em poucos tópicos (no máximo cinco assuntos); (iv) o moderador tem uma agenda na qual estão delineados os principais tópicos a serem abordados - os tópicos são, geralmente, pouco abrangentes, de modo que a discussão sobre eles se torna mais profunda; (v) pode haver a presença de observador externo, o qual não se manifesta, para captar reações dos participantes; (vi) os grupos focais não são úteis para inferências precisas a respeito de toda a população; (vii) utiliza questões e respostas não estruturadas, podendo contribuir apresentando novas ideias sobre o assunto que está sendo investigado; (viii) deve captar informações e não as dar.

As principais vantagens e desvantagens da técnica de grupo focal são apresentadas no Quadro 2.

Quadro 2 - Vantagens e desvantagens do grupo focal.

\begin{tabular}{|l|l|}
\hline \multicolumn{1}{|c|}{ Vantagens } & \multicolumn{1}{c|}{ Desvantagens } \\
\hline $\begin{array}{l}\text { Insight: por meio da troca de experiências e opini- } \\
\text { ões dos participantes, eles compreendem as cren- } \\
\text { ças, as atitudes, os pensamentos e as experiências } \\
\text { que estão presentes em seus comportamentos co- } \\
\text { tidianos e nos dos outros participantes,. }\end{array}$ & $\begin{array}{l}\text { Tendências grupais que podem levar à "conformi- } \\
\text { dade" ou à "polarização" dos assuntos. Há a possi- } \\
\text { bilidade de um participante mais comedido ter sua } \\
\text { opinião oprimida pelos outros participantes. }\end{array}$ \\
\hline $\begin{array}{l}\text { Levantamento de dados: são eficientes no levanta- } \\
\text { mento de dados sobre o tema do estudo. }\end{array}$ & $\begin{array}{l}\text { Quando o pesquisador está explorando determinado } \\
\text { assunto e não tem grande conhecimento sobre ele, } \\
\text { as informações obtidas através do grupo focal podem } \\
\text { ser generalizadas, sendo, assim, mais difíceis de serem } \\
\text { analisadas aprofundadas em uma pesquisa acadêmica. }\end{array}$ \\
\hline $\begin{array}{l}\text { Linguagem: com a interação, o moderador/pesqui- } \\
\text { sador passa a conhecer, mais detalhadamente, a a } \\
\text { linguagem que o grupo focal usa para descrever } \\
\text { suas experiências, seus valores, seus pensamentos } \\
\text { e seu processo de comunicação. }\end{array}$ & $\begin{array}{l}\text { Não garante total anonimato. Assim, temas polêmi- } \\
\text { cos ou constrangedores, tendem a levar os respon- } \\
\text { dentes a concordar com a opinião da maioria ou, } \\
\text { ainda, a não oferecerem respostas verdadeiras. }\end{array}$ \\
\hline $\begin{array}{l}\text { Dinâmica de grupo: pode ser um fator sinergético no no } \\
\text { fornecimento de informações, fazendo com que o pró- } \\
\text { prio participante reflita sobre fatores que ele não refle- } \\
\text { tiria sozinho, auxiliando a formação de argumentos e } \\
\text { reflexões, que serão acrescentadas em suas respostas. }\end{array}$ & $\begin{array}{l}\text { Depende da seleção criteriosa de participantes. Es- } \\
\text { colhê-los e convencê-los a participar do grupo focal } \\
\text { não é uma atividade simples e rápida. }\end{array}$ \\
\hline $\begin{array}{l}\text { Baixo Custo: dado que a interação de um grupo de } \\
\text { respondentes ocorre em uma única vez, o custo, } \\
\text { em termos de tempo, é baixo. }\end{array}$ & $\begin{array}{l}\text { As discussões podem ser desviadas ou dominadas } \\
\text { por poucas pessoas, de forma que, se cuidados não } \\
\text { forem tomados, os resultados representarão apenas } \\
\text { a opinião de poucos participantes, desvirtuando-se, } \\
\text { assim, do objetivo da interação grupal. }\end{array}$ \\
\hline
\end{tabular}




\begin{tabular}{|c|c|}
\hline Vantagens & Desvantagens \\
\hline $\begin{array}{l}\text { Rapidez: fornecem resultados rápidos, porque, ao } \\
\text { final do encontro do grupo focal, o moderador/pes- } \\
\text { quisador já tem um bom conjunto de respostas. }\end{array}$ & $\begin{array}{l}\text { Comentários devem ser interpretados no contexto do } \\
\text { grupo, uma vez que a realidade observada é específica ao } \\
\text { grupo selecionado, o qual está sujeito a especificidades. }\end{array}$ \\
\hline
\end{tabular}

De posse da descrição e da apresentação das vantagens e desvantagens das duas técnicas propostas, descrevem-se, comparativamente, as principais características da técnica Delphi e de grupo focal. Essa apresentação, de forma pareada, é importante para que se consiga vislumbrar um paralelo que sirva de pano de fundo para o pesquisador compreender qual delas pode ser a mais adequada dentro do seu contexto de pesquisa.

\section{COMPARATIVO ENTRE O MÉTODO DELPHI E O DE GRUPO FOCAL}

O Quadro 3 apresenta as principais características entre da técnica Delphi e de grupo focal.

Quadro 3 - Comparação entre Delphi e grupo focal.

\begin{tabular}{|c|c|c|}
\hline Descrição & Delphi & Grupo focal \\
\hline Distinções & $\begin{array}{l}\text { (i) Anonimato, (ii) interação com fee- } \\
\text { dback controlado, (iii) respostas esta- } \\
\text { tísticas do grupo. }\end{array}$ & $\begin{array}{l}\text { (i) Não possui anonimato, (ii) interação } \\
\text { com feedback não controlado no grupo, } \\
\text { (iii) respostas descritivas anotadas pelo } \\
\text { moderador, (iv) técnica dos "por quês?", } \\
\text { (v)confrontação face a face. }\end{array}$ \\
\hline Planejamento & $\begin{array}{l}\text { Questionários ou roteiros de entrevis- } \\
\text { tas intensivos intercalados. }\end{array}$ & $\begin{array}{l}\text { De três a cinco questões de orientação } \\
\text { que guiarão as sessões. }\end{array}$ \\
\hline $\begin{array}{l}\text { Foco do estudo } \\
\text { (pesquisa) }\end{array}$ & $\begin{array}{l}\text { Estudos de prospecção (previsão e estima- } \\
\text { tivas de futuro); inteligência de grupo. }\end{array}$ & Eventos presentes e futuros. \\
\hline Objetivo & $\begin{array}{l}\text { Definir bem o problema de pesquisa e } \\
\text { desenvolver uma estrutura conceitual } \\
\text { para ela. }\end{array}$ & $\begin{array}{l}\text { Obtenção de dados preliminares em um } \\
\text { estudo qualitativo. }\end{array}$ \\
\hline $\begin{array}{l}\text { Convite aos } \\
\text { participantes }\end{array}$ & $\begin{array}{l}\text { Especialistas com experiência no as- } \\
\text { sunto. }\end{array}$ & $\begin{array}{l}\text { Pessoas com experiência no assunto ou } \\
\text { em eventos que tratem sobre o tema. }\end{array}$ \\
\hline $\begin{array}{l}\text { Instrumento } \\
\text { de pesquisa }\end{array}$ & Estruturado. & Semiestruturado. \\
\hline $\begin{array}{l}\text { Aplicação dos } \\
\text { questionários }\end{array}$ & $\begin{array}{l}\text { Dois ou mais vezes rounds, até que al- } \\
\text { guns critérios pré-estabelecidos sejam } \\
\text { contemplados, como a obtenção do } \\
\text { consenso ou quase consenso de maior } \\
\text { parte do grupo. }\end{array}$ & $\begin{array}{l}\text { O número de sessões varia de acordo } \\
\text { com a necessidade da pesquisa e deve } \\
\text { estar de acordo com a quantidade de as- } \\
\text { suntos a serem investigados. }\end{array}$ \\
\hline Amostra & $\begin{array}{l}\text { Não existe consenso sobre a quantida- } \\
\text { de de especialistas, podendo variar de } \\
\text { dez a trinta especialistas. }\end{array}$ & $\begin{array}{l}\text { Não existe consenso sobre a quantidade } \\
\text { de componentes do grupo, podendo va- } \\
\text { riar de quatro a doze participantes. }\end{array}$ \\
\hline $\begin{array}{l}\text { Condução da } \\
\text { pesquisa }\end{array}$ & $\begin{array}{l}\text { Presença de um moderador, responsá- } \\
\text { vel pela construção dos questionários e } \\
\text { relatórios de feedback do grupo. }\end{array}$ & $\begin{array}{l}\text { Presença de um moderador/pesquisador } \\
\text { para a condução dos debates. }\end{array}$ \\
\hline $\begin{array}{l}\text { Procedimentos da } \\
\text { coleta de dados }\end{array}$ & $\begin{array}{l}\text { Dinâmica de grupo, possibilidade de gra- } \\
\text { vação das sessões, realização por meio } \\
\text { eletrônico (grupo focal eletrônico). }\end{array}$ & $\begin{array}{l}\text { Correio, e-mail, possibilidade de realiza- } \\
\text { ção através de sites na WEB (web Delphi) } \\
\text { protegidos por senha na rede. }\end{array}$ \\
\hline Análise dos dados & \begin{tabular}{|l|} 
Estatística descritiva, distribuição esta- \\
tística da distribuição dos resultados.
\end{tabular} & $\begin{array}{l}\text { Fenomenologia, análise de conteúdo ou } \\
\text { de discurso etc. }\end{array}$ \\
\hline $\begin{array}{l}\text { Abordagem dos } \\
\text { dados (representação) }\end{array}$ & Qualitativa. & Qualitativa. \\
\hline
\end{tabular}


UM ESTUDO SOBRE AS CARACTERÍSTICAS DO MÉTODO DELPHI E DE GRUPO FOCAL, COMO TÉCNICAS NA OBTENÇÃO DE DADOS EM PESQUISAS EXPLORATÓRIAS

\begin{tabular}{|l|l|l|}
\hline \multicolumn{1}{|c|}{ Descrição } & \multicolumn{1}{c|}{ Delphi } & \multicolumn{1}{c|}{ Grupo focal } \\
\hline $\begin{array}{l}\text { Resultados da } \\
\text { pesquisa em formato }\end{array}$ & Quantitativa/Qualitativa. & Qualitativa. \\
\hline Operacionalização & $\begin{array}{l}\text { Não faz confrontação face a face entre } \\
\text { os participantes. }\end{array}$ & $\begin{array}{l}\text { Inúmeras ideias dos participantes e con- } \\
\text { frontação de opiniões. }\end{array}$ \\
\hline
\end{tabular}

Fonte: Elaborado pelo autor.

Ao descrever as principais diferenças entre a técnica Delphi e de grupo focal, percebe-se que ambas visam obter o consenso de opiniões da maior parte de um grupo sobre determinado assunto de pesquisa. Entretanto, as suas formas de operacionalização diferem-se. No método Delphi, as respostas são obtidas individualmente de cada especialista pesquisado, sem a interação e influência do grupo. Já no método de grupo focal, obtém-se ganhos com a interação do grupo, com a sua participação em discussões sobre o assunto que está sendo pesquisado.

A pesquisa Delphi tende a ser mais formal e objetiva do que a do grupo focal, pois, na pesquisa Delphi, a abordagem é fazer, pessoal e diretamente, perguntas previamente elaboradas aos especialistas, de modo a obter sua opinião, individualmente, repetidas vezes. Assim, o pesquisador analisa as respostas e os feedbacks, procurando o consenso de opiniões por meio de rounds de questionários, sem que haja interação entre os especialistas participantes do grupo. Uma das vantagens do grupo Delphi em relação ao grupo focal é evitar o confronto entre os especialistas, não havendo necessidade de geração de expectativas nas interações para que os participantes se sintam à vontade como ocorre no grupo focal, pois as perguntas são pessoais.

O principal benefício do grupo focal para a pesquisa exploratória está no auxílio à formulação de hipóteses, pois a discussão do grupo possibilita clareza de pensamento aos participantes do grupo, e à identificação de novos conceitos e de novas ideias para estudos vindouros.

Nessa técnica, o moderador apresenta questionamentos ao grupo, que pode estar reunido em um ambiente ou mesmo na Internet (grupo eletrônico). A seguir, dada a interação entre os participantes do grupo, vão obtendo-se informações acerca do assunto proposto.

Em suma, são técnicas distintas que apresentam diferentes meios para a coleta de opinião de um grupo de especialistas, e cujos resultados também podem ser diferentes. É importante que o pesquisador esteja atento a essas diferenças e, numa situação em que não possa contar com as duas técnicas, ele possa escolher aquela que melhor Ihe convém, dado seu contexto de pesquisa.

Nesse sentido, caso o pesquisador necessite de mais argumentos e reflexões sobre o assunto objeto da pesquisa, o grupo focal é o mais adequado, p0ois, por meio da discussão sobre tópicos previamente selecionados, os componentes do grupo apresentam suas opiniões sobre o assunto e, com o aprofundamento da discussão, o pesquisador pode obter mais respostas através de sondagens sobre as razões ocultas em relação a um determinado comportamento dos participantes.

$\mathrm{Na}$ pesquisa Delphi, devido ao anonimato dos participantes, suas são obtidas individualmente, não estando sujeitas à análise e discussão por meio de reuniões face a face pelos componentes do grupo. Já na pesquisa de grupo focal, o método é qualitativo, não necessitando de medidas numéricas e análises estatísticas. Destarte, se a pesquisa for realizada por meio de grupo focal, o pesquisador irá interagir diretamente com o ambiente do contexto da pesquisa, tendo em vista obter seus julgamentos e percepções. 


\section{CONSIDERAÇÕES FINAIS}

As pesquisas em Administração possuem várias técnicas que podem ser empregadas para a obtenção dos dados. É por meio dos objetivos da pesquisa que se definido o plano de execução a ser utilizado para a obtenção dos dados da pesquisa. Nessa perspectiva, o presente estudo teve por objetivo descrever as principais características do método de pesquisa Delphi e de grupo focal, como as técnicas de entrevistas exploratórias, tendo em vista realizar uma comparação entre os dois métodos que auxilie a escolha do mais adequado para o pesquisador.

Os resultados demonstram que o método Delphi apresenta algumas características dessemelhantes do método de grupo focal, tais como: o anonimato dos respondentes, a representação estatística dos resultados (estatística da distribuição dos resultados) e o feedback de respostas dos grupos para reavaliação nas rodadas subsequentes. No grupo focal, os dados são obtidos pela interação com o grupo e podem ser interpretados por diferentes métodos, como pela fenomenologia (aquilo que é exposto pelo grupo e como ele observa o mundo) pela análise de conteúdo ou pela análise de discurso.

Os resultados demonstram, ainda, que os benefícios da técnica Delphi, para as pesquisas exploratórias, estão na interação que ocorre na discussão sobre assuntos por parte dos especialistas, de forma individual e, repetidas vezes, fator que leva à espontaneidade. Por outro lado, apesar de o processo ser dinâmico, os assuntos carecem de reflexão e de respostas mais elaboradas.

Os principais benefícios do grupo focal para as pesquisas exploratórias estão no: (i) auxílio à formulação de hipóteses, pois a discussão oferece clareza de pensamento, ajudando a expressar proposições de pesquisa; (ii) auxílio à identificação de conceitos relevantes para uma pesquisa, que pode ser a característica de um produto ou um serviço, autuando na definição operacional de um conceito, na identificação e no teste de novas ideias de pesquisa. A técnica de pesquisa de grupo focal não é recomendada para discutir questões delicadas, como quando estão evidenciados na pesquisa problemas pessoais dos respondentes componentes do grupo, nem para testar hipóteses.

Denota-se que ambos os métodos (Delphi e de grupo focal) possuem contribuições eficientes para o levantamento de dados para pesquisas de natureza exploratória, utilizadas quando o pesquisador possui poucas informações sobre o assunto a ser tratado.

\section{LIMITAÇÕES E RECOMENDAÇÕES PARA ESTUDOS FUTUROS}

Como limitação da presente discussão, considera-se que as técnicas metodológicas abordadas (Delphi e grupo focal) tenham sido consideradas interdependentes entre si. Não foram abordadas as intersecções existentes entre as técnicas e não se considerou a possibilidade de triangulação de métodos, tal como propõe Denzin (1978). Ainda que essa possa ser uma abordagem possível, conforme se discutiu na Introdução deste estudo, preferiu-se optar por oferecer uma análise pareada entre as diferentes técnicas, já que a realidade do pesquisador brasileiro, comumente, é restrita em termos de recursos, o que o leva a optar por uma técnica sem complementá-la com outras. Todavia, ressalta-se que essas restrições não justificam uma eventual fraqueza ou desvantagem da pesquisa oriunda de uma técnica específica, ou ainda, a limitação de robustez que poderia ser atingida pela triangulação. Trata-se apenas de uma remediação a uma situação existente nas práticas de pesquisa nacionais, nas quais os pesquisadores devem 
estar cientes dos prós e contras de suas escolhas metodológicas, fazendo uma escolha consciente da técnica mais adequada perante o contexto de sua pesquisa.

Como recomendação para continuidade da discussão aqui estabelecida, recomendase que outras técnicas de pesquisa, principalmente as oriundas de pesquisas exploratórias, sejam colocadas lado a lado numa comparação peer-to-peer. Dessa forma, quando os quadros comparativos estiverem elaborados e forem colocados num mesmo plano, será possível criar um mapa comparativo final, capaz de dar uma visão mais completa das técnicas disponíveis para pesquisa, o que facilitaria uma futura escolha metodológica, servindo de suporte para ela. 


\section{REFERÊNCIAS}

ANDRADE, M. M. Como preparar trabalhos para cursos de pós-graduação. Noções práticas. 5a Ed. São Paulo: Atlas, 2002.

BENARIE, M. Delphi- and Delphilike approaches with special regard to environmental standard setting. Technological Forecasting and Social Change, v. 33, n. 2, p. 149-158, 1988.

BLOOR, M.; FRANKLAND, J.; THOMAS, M.; ROBSON, K. Focus groups in social research. Thousand Oaks: Sage, 2001.

CARNEIRO DA CUNHA, J. A. Avaliação de desempenho e eficiência em organizações de saúde: um estudo em hospitais filantrópicos. Tese de (Doutoramento). Faculdade de Economia, Administração e Contabilidade. Universidade de São Paulo. 2011.

COLLIS, J.; HUSSEY, R. Pesquisa em Administração. Um guia prático para alunos de graduação e pós-graduação. 2a $\mathrm{Ed}$. Porto Alegre: Bookman, 2005.

CORTÉS-REYES, E. From agreements to consensus. Colombian Journal of Anesthesiology, v. 40, n. 2, p. 134-136, 2012.

DALKEY, N. C. The Delphi method. An experimental study of group opinion. Santa Monica: Rand Corporation, 1969.

DALKEY, N; HELMER, O. An experimental application of the Delphi method to the use of experts. Management Science, v.9, n. 3, p. 458-467, 1963.

DE ANTONI, C.; MARTINS, C.; FERRONATO, M. A.; SIMÕES, A.; MAURENTE, V.; COSTA, F.; KOLLER, S. H. Grupo focal: Método qualitativo de pesquisa com adolescentes em situação de risco. Arquivos Brasileiros de Psicologia, v. 53, n. 2, p. 38-53, 2001.

DEBUS, M. Manual de excelência em la investigación mediante grupos focales. In: E.
Esperidião (org.). Reflexões sobre a utilização do grupo focal como técnica de pesquisa. São Paulo: Fundação Editora de UNESP, 2004.

DENZIN, N. K. The researchact. A theoretical introduction to sociological methods. 2a $\mathrm{Ed}$. Chicago: Aldine Publishing Company, 1978.

Moments, mixed methods, and paradigm dialogs. Qualitative Inquiry, v. 16, n. 6, p. 419-427, 2010.

EGAN, A. F.; JONES, S. B.; LULOFF, A. E.; FINLEY, J. C. The value of using multiple methods: An illustration using survey, focus group, and Delphi techniques. Society \& Natural Resources: An International Journal, v. 8, n. 5, p. 457-465, 1995.

FLICK, U. Introdução à pesquisa qualitativa. $3^{a}$ Ed. Porto Alegre: Bookman, 2009.

GIL, A. C. Métodos e técnicas de pesquisa social. 5a Ed. São Paulo: Atlas, 1999.

GLASER, G. B.; STRAUSS, A. L. The discovery of grounded theory. Strategies for qualitative research. New York: Aldine, 1967.

GOMES, M. E. S., BARBOSA, E. F. A técnica de grupos focais para obtenção de dados qualitativos. Educativa - Instituto de Pesquisas e Inovações Educacionais. 1999. Disponível em: http://www.tecnologiadeprojetos.com. br/banco_objetos/\%7B9FEA090E-98E9-49D2A638-6D3922787D19\%7D_Tecnica\%20de\%20 Grupos\%20Focais\%20pdf.pdf Acesso em: 20/ jul/2012.

GREENBAUM, T.L. The handbook for focus group research. 2a Ed. Thousand Oaks: Sage, 1998.

HAIR, J. F.; BABIN, B.; MONEY, A. H.; SAMOUEL, $P$. Fundamentos de métodos de pesquisa em administração. Porto Alegre: Bookman, 2007.

HASSON, F.; KEENEY, S.; MCKENNA, H. Research guidelines for the Delphi technique.Journal of Advanced Nursing, v. 32, n. 4, p. 1008-1015, 2000. 
HUGHES, D.; DUMONT, K. Using focus groups to facilitate culturally anchored research. American Journal of Community Psychology, v. 21, n. 6, p. 775-806, 1993.

JICK, T. D. Mixing qualitative and quantitative methods: Triangulation in action. Administrative Science Quarterly, v. 24, n. 4, p. 602-611, 1979.

KRUEGER, R. A.; CASEY, M. A. Focus groups. A practical guide for applied research. 3 a Ed. Thousand Oaks: Sage, 2000.

LANDETA, J.; BARRUTIA, J.; LERTXUNDI, A. Hybrid Delphi: A methodology to facilitate contribution from experts in professional contexts. TechnologicalForecastingand Social Change, v. 78, n. 9, p. 1629-1641, 2011.

MARION, J. C.; DIAS, R.; TRALDI, M. C. Monografia para os cursos de administração, contabilidade e economia. São Paulo: Atlas, 2002.

MATTAR, F. N. Pesquisa de marketing. São Paulo: Atlas, 1994.

LIMA, M. O.; PINSKY, D.; IKEDA, A. A. A utilização do Delphi em pesquisas acadêmicas em administração: um estudo nos anais do EnAnpad. In XI SemeAd (Seminários de Administração FEA-USP), 2008, São Paulo. Anais...São Paulo: FEA-USP.

LINSTONE, H. A.; TUROFF, M.The Delphi method: techniques and applications. Boston: Addison-Wesley, 1975.

MEYRICK, J. The Delphi method and health research. v. 103, n.1, p. 7-16, 2003.

MORGAN, D. L. Focus group as qualitative research. 2a Ed. Qualitative Research Method Series, 16. Thousand Oaks: Sage, 1997.

MORGAN, D. L.; SPANISH, M. T. Focus groups: A new tool for qualitative research. Qualitative Sociology, v. 7, n. 3, p. 253-270, 1984.
C.; MARCHIORI, P. Z. Introdução ao Método Delphi. Curitiba: Mundo Material, 2008 (manual didático).

RÉVILLION, A.S.P.A Utilização de Pesquisas Exploratórias na Área de Marketing.In Trabalhos apresentados XXV EnANPAD 2001. Campinas.SP.

Disponível em: http://www.anpad.org.br/ evento.php?cod_evento_edicao=5 Acesso em 07/12/2012.

RICHARDSON, R. (coord.) et al. Pesquisa social - métodos e técnicas. São Paulo: Atlas, 1989.

SACKMAN, H. Summary evaluation of Delphi. Policy Analysis, v. 1, n. 4, p. 693-718, 1975.

SÁFADI, C. M. Q. Delphi: um estudo sobre sua aceitação. In IV SemeAd (Seminários de Administração FEA-USP), 2001, São Paulo. Anais...São Paulo: FEA-USP.

SCHINDLER, P.S., COOPER, D.R. Métodos de pesquisa em administração. 7ạ Edição. São Paulo.Artmed - Editora S/A. 2001.

SIM, J. Collecting and analyzing qualitative data: Issues raised by the focus group. Journal of Advanced Nursing, v. 28, n. 2, p.345-352, 1998.

STEBBINS, R. A. Exploratory research in the social sciences.Qualitative research method series 48. Thousand Oaks, Sage, 2001.

STEWART, D. W.; SHAMDASANI, P. N.; ROOK, D. W. Focus groups. Theory and practice. 2a Ed. Applied Social Research Methods Series, 20. Thousand Oaks: Sage, 2007.

VERGARA, S. C. Métodos de pesquisa em administração. 3ạ Ed. São Paulo: Atlas, 2008.

OLIVEIRA, J. S. P.; COSTA, M. M.; WILLE, M. F. 